(2) Open Access Full Text Article

REVIEW

\title{
latrogenic disease in the elderly: risk factors, consequences, and prevention
}

This article was published in the following Dove Press journal:

Clinical Interventions in Aging

I8 March 201 I

Number of times this article has been viewed

\section{Sompol Permpongkosol \\ Division of Urology, Department of Surgery, Faculty of Medicine, Ramathibodi Hospital, Mahidol University, Bangkok, Thailand}

Correspondence: Sompol Permpongkosol Division of Urology, Department of Surgery, Faculty of Medicine, Ramathibodi Hospital, Mahidol University, Rama 6 Road, Bangkok 10400, Thailand

Tel $+662201 \quad 1315$

Fax +662 20I I3I5

Email sompolpermpong@gmail.com

\begin{abstract}
The epidemiology of iatrogenic disease in the elderly has not been extensively reported. Risk factors of iatrogenic disease in the elderly are drug-induced iatrogenic disease, multiple chronic diseases, multiple physicians, hospitalization, and medical or surgical procedures. Iatrogenic disease can have a great psychomotor impact and important social consequences. To identify patients at high risk is the first step in prevention as most of the iatrogenic diseases are preventable. Interventions that can prevent iatrogenic complications include specific interventions, the use of a geriatric interdisciplinary team, pharmacist consultation and acute care for the elderly units.
\end{abstract}

Keywords: iatrogenic disease, elderly, risk factors, prevention

\section{Introduction}

The definition of the term "elderly" varies widely in the medical literature, the most common lower limits being 60, 65, 70, 75, and 80 years. ${ }^{1}$ The term "elderly" comes from the Anglo-Saxon word "eld", which forms the root of words that convey wisdom accrued from age and experience. ${ }^{2}$ The word "iatrogeny" derives from Greek and refers to any pathologic alteration caused to a patient by the inappropriate practice of health professionals, which results in harmful consequences for the patient's health. ${ }^{3}$ According to the World Health Organisation, iatrogenic disease may be defined as adverse drug reactions or complications induced by nondrug medical interventions. ${ }^{4}$ In addition, iatrogenic disease has been defined by Darchy et $\mathrm{al}^{5}$ as a disease induced by a drug prescribed by a physician, after a medical or surgical procedure (excluding intentional overdose, nonmedical intervention) unauthorized prescription, and environmental events (eg, falls, defective equipment). However, it has to be kept in mind that, by definition, an adverse drug reaction differs from an adverse drug event, in that the former is an outcome attributable to a drug, whereas the latter, while associated with medication intake, is not necessarily so. ${ }^{6}$

Iatrogenic disease is an important cause of both death and illness among older people, and occurs in all aspects of medical practice, starting with the patient-doctor relationship, and including diagnosis, treatment, and, finally, prevention of disease. ${ }^{3}$ This article reviews the epidemiology, risk factors, consequences, and prevention of iatrogenic disease in the elderly.

\section{Epidemiology}

The epidemiology of iatrogenic disease in the elderly has not been precisely reported. However, it is possible to make estimates from previous publications related to 
iatrogenic disease. A recent meta-analysis showed the incidence of iatrogenic disease to be between $3.4 \%$ and $33.9 \% .^{4}$ In 1998 , Darchy et $\mathrm{al}^{5}$ reported that of 623 patients admitted to the intensive care unit, 68 (10.9\%) were considered to be iatrogenic cases. The causes of iatrogenic disease were drugs in 41 cases, medical interventions in 12 , and surgical interventions in 15. Risk factors for iatrogenic disease were old age and the number of prescribed drugs. These iatrogenic complications included adverse drug effects (eg, interactions), falls, nosocomial infections, pressure areas, delirium, and complications related to surgery. In 2003, Peyriere et $\mathrm{al}^{7}$ reported that the rate of avoidability of adverse drug events as a cause for admission in internal medicine or when occurring during hospitalization was $57.9 \%$. These adverse events were associated with therapeutic errors, such as inappropriate drug administration, drug-drug interactions, and dosage error. Patients with adverse drug events stayed longer in hospital and took more drugs, both before and during their hospital stay $(P<0.05)$. Recently, Mercier et al reported that $19.5 \%$ of intensive care unit admissions resulted from iatrogenic events, with a high proportion of shock, leading to a greater need for invasive treatments and longer stays in the intensive care unit. ${ }^{8}$

Epidemiological studies performed by pharmacists and epidemiologists produced lower incidences than those of internists. Atiqi et al reassessed the prevalence of iatrogenic admissions reported in a study done by internists. ${ }^{4}$ Most often, iatrogenic admissions were observed with cardiac disease, hypertension, gastrointestinal conditions, anticoagulant treatment, and use of nonsteroidal anti-inflammatory drugs. At least $19 \%$ of admissions were to departments of internal medicine, cardiology, and pulmonology, and up to $29 \%$ of these admissions were suspected to be attributable to adverse drug effects. Interestingly, a large difference was observed between the number of iatrogenic admissions according to the admitting physicians and the investigators (229 versus 380 , respectively). Aranaz-Andres et al demonstrated that patients older than 65 years of age had a higher frequency of adverse events than those under this age $(12.4 \%$ versus $5.4 \%$, $P<0.001$, relative risk 2.5) in Spanish hospitals. ${ }^{9}$

Studies of US patients aged over 65 years indicate that each year, more than 180,000 life-threatening or fatal adverse drug effects occur in the outpatient setting, of which at least half may be preventable. ${ }^{10}$ Finally, iatrogenic pathology in the elderly population has an even bigger impact due to the conjugation of two major demographic phenomena, ie, an absolute and percentage increase in the elderly population in parallel with an increased prevalence of iatrogenic pathology with age. ${ }^{11}$

\section{Risk factors}

Elderly patients have more comorbidities than their younger counterparts. An increased incidence of adverse drug events in elderly patients may be explained by the increased number of pathologies or disease states present in the elderly, and the number of drugs taken on a long-term basis, resulting in alteration in excretion and elimination processes (kidneys, liver) and changes in plasma protein levels (eg, hypoalbuminemia). This increased exposure to medical interventions increases the risk for adverse consequences of care. To identify patients at high risk is the first step in prevention, and most iatrogenic diseases are avoidable. ${ }^{7}$

\section{Drug-induced iatrogenic disease}

Multiple medications (polypharmacy) that transform the elderly into living "chemistry sets", are probably the most ubiquitous threats for iatrogenic disease. In a study of elderly patients, a high number of daily drugs increased the risk of drug interactions responsible for iatrogenic illnesses in $12.6 \%$ of cases. ${ }^{12}$ Taking multiple drugs concurrently and having multiple chronic diseases markedly increase the risk of adverse drug-drug or drug-disease interactions. The risk of such interactions is particularly high among patients who are malnourished or who have renal failure. ${ }^{13}$ Also, certain drugs have a particularly high risk of causing adverse effects in the elderly.

Several studies on falls in the elderly have reported that laxatives can be a risk factor. However, there is no proven causal link between laxative drugs and falls. A recent metaanalysis ${ }^{14}$ showed that elderly subjects treated with laxatives were twice as likely to fall compared with nonlaxative users. The causal relationship was probably not directly linked with a side effect of the substance used, but rather a reflection of other pathologies that may cause falls. These pathologies included older age, confinement to bed, or concomitant Parkinson's disease.

\section{Multiple chronic diseases}

The greater the number of chronic diseases, the greater the risk that treatment of one disease will exacerbate other conditions. For example, treatment of arthritis with a nonsteroidal anti-inflammatory drug may exacerbate heart failure, coronary artery disease, or chronic gastritis. ${ }^{13}$ 


\section{Multiple physicians}

Misdiagnosis, including both overtreatment and undertreatment, is a recurrent problem in the elderly. Having multiple physicians can result in uncoordinated care and unnecessary polypharmacy. As a result, a patient's therapeutic regimen is frequently changed without the input of the patient's other physicians, thereby increasing the risk of iatrogenic complications. ${ }^{13}$

\section{Hospitalization}

Hospitalization of nursing home residents is costly, and potentially exposes residents to iatrogenic disease and psychological harm. ${ }^{15}$ Jahnigen et al reported a disproportionately high incidence of iatrogenic diseases in hospitalized patients over the age of 65 years. ${ }^{16}$ Foster et al demonstrated that intensive care unit-based adverse events are common, and have a large impact on length of hospital stay. ${ }^{17}$ They estimated that adverse events were independently associated with an average increase in hospital stay of 31 days. This study reaffirms the importance of improving patient safety in the intensive care unit by monitoring the risk of adverse events.

\section{Medical or surgical procedures}

Several of the risks for iatrogenic disease are amenable to control. Risks due to hospitalization include hospitalacquired infection, polypharmacy, and transfusion reactions. Hospitalized patients who have dementia or who are immobilized (eg, after surgery) are at high risk of iatrogenic complications.

Medical technology may contribute to iatrogenic complications, including sudden death or myocardial infarction after valve replacement surgery, stroke after carotid endarterectomy, fluid overload after transfusions and infusions, unwanted prolongation of life via artificial life support, and hypoxic encephalopathy after potentially life-prolonging cardiopulmonary resuscitation.

For epidural anesthesia, Date et al reported that epidural catheters were misplaced in the subarachnoid space in six cases and in the thoracic cavity in two cases over a period of eight years (1999-2007) at an urban university hospital. ${ }^{18}$ In urology, Permpongkosol et al ${ }^{19}$ reported their experience with laparoscopic extravesical neoureterocystostomy for iatrogenic distal ureteral stricture using a transperitoneal intracorporeal freehand suturing technique. One patient, a 77-year-old male, underwent a Lich-Gregoir antireflux ureteral reimplantation following complications arising from transurethral resection of the prostate.

\section{Consequences}

In 1980, the World Health Organisation introduced a new system of classification related to the consequences of disease, known as the "International Classification of Impairments, Disabilities, and Handicaps". Clinicians must know how iatrogenic disease presents in the elderly and how to manage it. Because one of the hallmarks of aging seems to be a loss of reserve capacity, and hence a loss of ability to respond to stress, many older persons may fail to exhibit the characteristic symptoms associated with a given disease.

Moreover, most of the elderly suffer from several chronic conditions, making it difficult to distinguish clearly a symptom of iatrogenic disease in the context of coexisting problems. A diagnosis of iatrogenic disease thus requires a substantial degree of insight and subtlety. Iatrogenic disease can happen to anyone, especially amongst the elderly, and may have quite traumatizing psychomotor and social consequences. As a consequence of iatrogenic disease, the patient may become dependent on a third person, and may no longer be able to leave their home. Iatrogenic disease produced as a result of medical intervention may lead to confusion in certain cases during investigation and postmortem examination. For example, Chattopadhyay and Pal reported a rare case in which the iatrogenic injuries produced by a medical practitioner during the course of treatment of a case of suicidal hanging resulted in suspicion being raised as to the nature of the death. $^{20}$

\section{Prevention}

A preventable event may be defined as an event that would not occur if medical science can provide optimal management. Prevention remains the best guarantee of good quality of life, and can decrease the social and economic costs of illness. ${ }^{21}$ However, older patients and those with a greater number of health problems have been shown to be at increased risk of preventable adverse events. ${ }^{22}$

Identification of the elderly who are at high risk, minimization of medication, early recognition and treatment of illness, and close management of chronic illness, are necessary components of preventive care. Mercier et al reported that $73.8 \%$ of iatrogenic events in their study of intensive care unit cases seemed preventable. ${ }^{8}$

The traditional tripartite division of prevention into primary, secondary, and tertiary prevention is difficult to maintain when considering the healthcare needs of older people. ${ }^{23,24}$ Primary prevention aims to stop iatrogenic disease before it starts, usually by reducing or eliminating 
risk factors. In secondary prevention, iatrogenic disease is detected and treated at an early stage, before symptoms or functional losses occur, thereby minimizing morbidity and mortality. In tertiary prevention, an existing symptomatic, usually chronic, iatrogenic disease is appropriately managed to prevent further functional loss. Iatrogenic disease is the most preventable problem among the elderly. Interventions that can prevent iatrogenic complications are now discussed.

\section{Specific interventions}

Up to $50 \%$ of adverse events that occur in hospitals are preventable. Care managers who facilitate communication among healthcare practitioners should ensure that the required services are provided, and prevent duplication of these services. ${ }^{13}$ Language barriers and disabilities that affect communication have been shown to decrease quality of care. ${ }^{22}$ Patients with communication problems appeared to be at highest risk for preventable adverse events. Interventions to reduce the risk for these patients need to be developed and evaluated.

Some specific interventions to reduce iatrogenic disease have been tested. A randomized controlled trial showed that a letter from the general practitioner was highly effective in reducing benzodiazepine use among older people. ${ }^{24,25}$ Care managers may be employed by physician groups, health plans, or community or governmental organizations. The frail elderly benefit most from case management. Management of the hospitalized elderly must be multidisciplinary, and should take into account the particular clinical and therapeutic characteristics of such a population. To decrease the incidence of adverse drug events, better use of drugs is needed, especially in the elderly. Most iatrogenic disorders can be avoided by using simple precautions, ie, increased knowledge of contraindications, restriction of self-medication, and lowering the number of concomitant drugs. ${ }^{7}$ The implementation of a nursing education program may significantly decrease the incidence of iatrogenic urethral injury, thereby improving patient safety. ${ }^{26}$

\section{Geriatric interdisciplinary team}

The comprehensive multidimensional assessment of older people is one of the cornerstones of the specialty of geriatric medicine. A geriatric interdisciplinary team evaluates all of the patient's needs, develops a coordinated care plan, and manages (or, along with the primary care physician, comanages) care. Because this intervention is resourceintensive, it is best reserved for very complex cases. ${ }^{13}$
With improved collaboration between physicians and healthcare practitioners who specialize in drug safety, physicians could become more aware of adverse drug events. In addition, close contact between patients and nurses allows nurses to play a leading role in the prevention and detection of adverse drug events. ${ }^{7}$

A study by Dos Santos and Ceolim ${ }^{27}$ suggests the importance of devising methods to encourage nursing professionals to report iatrogenic events accurately, as well as to create wards specifically for the elderly population. However, their report was not detailed and failed to indicate interventions which could prevent new occurrences.

Blinderman raised the issue of opioid-related iatrogenic harm, and discusses what counts as medical error in these circumstances, suggesting that palliative care specialists have a unique responsibility to provide guidance and establish a standard of care that all clinicians should adhere to. ${ }^{28}$

\section{Pharmacist consultation}

A pharmacist can help to minimize the potential complications caused by polypharmacy and inappropriate drug use. ${ }^{13}$ The authors of a previous meta-analysis urged prescribers to change their habits with respect to the management of constipation in elderly subjects. ${ }^{14}$ The risk/benefit ratio of the drugs administered could be improved with better knowledge of the patients' medical histories and risk factors for adverse drug events. ${ }^{7}$

Clinical guidelines are often based on the results of clinical trials conducted in young subjects with a lower level of disease complexity. ${ }^{29}$ Therefore, the recommendations of clinical guidelines may be difficult to apply to older adults. Fusco et al presented a rationale and methodology in CRIME (the Development of CRIteria to assess appropriate Medication use among the Elderly), translating the recommendations of general clinical guidelines to this type of patient. ${ }^{29}$ As well as being alert to the possibility of new iatrogenic problems, it is also prudent to reassess a patient's entire drug regimen at least twice a year, including categories often overlooked by patients and doctor, ie, drugs bought over the counter and "nutraceuticals", such as herbal remedies or dietary supplements. ${ }^{10}$

\section{Acute care for the elderly units}

Traditionally, acute medical care has been insufficient to meet the complex care needs of frail older adults. ${ }^{30}$ These units are in hospital wards with protocols to ensure that elderly patients are thoroughly evaluated for potential iatrogenic problems before they occur, and any such problems are identified and 
appropriately managed. ${ }^{13}$ Ahmed and Pearce showed acute care for the elderly units to be associated with positive global outcomes (eg, cost, length of stay, readmission rates, utilization, rehabilitation, cognition, function, patient/staff satisfaction). Further research has pointed to a decreased incidence of delirium and polypharmacy. ${ }^{30}$

Ou et $\mathrm{al}^{31}$ reported that a surgeon's expertise in biliary surgery, preoperative imaging, precise operative procedures, and conversion from laparoscopic to open cholecystectomy when needed, are important measures to prevent common bile duct injuries. Iatrogenic urethral injuries are a substantial source of preventable morbidity in hospitalized male patients. The implementation of a nursing education program may significantly decrease the incidence of iatrogenic urethral injury and, thereby improve patient safety. ${ }^{26}$

Bunting et $\mathrm{al}^{31}$ published an article to equip physicians with an adequate working knowledge of risk management and quality management information, which will enable them to practice more effectively in today's litigious and regulatory climate. ${ }^{32}$

Patients are encouraged to prepare advance directives, including designation of a proxy to make medical decisions. ${ }^{13}$ These documents can help prevent unwanted treatment for critically ill patients who cannot speak for themselves.

\section{Conclusion}

Iatrogenic disease in the elderly population has a particularly significant impact due to the conjugation of major demographic phenomena. Multiple drugs, multiple physicians, multiple chronic diseases, hospitalization, and disease arising from medical or surgical procedures increase the risk of iatrogenic disease in the elderly. Iatrogenic disease may have a significant psychomotor impact and devastating social consequences. Interventions that can prevent iatrogenic complications include a geriatric interdisciplinary team, pharmacist consultation, acute care for the elderly units, and advance directives.

\section{Disclosure}

The author reports no conflict of interest in this work.

\section{References}

1. Schmitt R, Coca S, Kanbay M, Tinetti ME, Cantley LG, Parikh CR. Recovery of kidney function after acute kidney injury in the elderly: A systematic review and meta-analysis. Am J Kidney Dis. 2008;52(2): 262-271.

2. Chronopoulos A, Cruz DN, Ronco C. Hospital-acquired acute kidney injury in the elderly. Nat Rev Nephrol. 2010;6(3):141-149.

3. Pereira AC, Franken RA, Sprovieri SR, Golin V. Iatrogeny in cardiology. Arq Bras Cardiol. 2000;75(1):75-78. Spanish.
4. Atiqi R, van Bommel E, Cleophas TJ, Zwinderman AH. Prevalence of iatrogenic admissions to the Departments of Medicine/Cardiology/ Pulmonology in a 1,250 bed general hospital. Int J Clin Pharmacol Ther. 2010;48(8):517-524.

5. Darchy B, Le Miere E, Figueredo B, Bavoux E, Cadoux G, Domart Y. Patients admitted to the intensive care unit for iatrogenic disease. Risk factors and consequences. Rev Med Interne. 1998;19(7):470-478. French.

6. Cresswell KM, Fernando B, McKinstry B, Sheikh A. Adverse drug events in the elderly. Br Med Bull. 2007;83:259-274.

7. Peyriere H, Cassan S, Floutard E, et al. Adverse drug events associated with hospital admission. Ann Pharmacother. 2003;37(1):5-11.

8. Mercier E, Giraudeau B, Ginies G, Perrotin D, Dequin PF. Iatrogenic events contributing to ICU admission: A prospective study. Intensive Care Med. 2010;36(6):1033-1037.

9. Aranaz-Andres JM, Aibar-Remon C, Vitaller-Murillo J, Ruiz-Lopez P, Limon-Ramirez R, Terol-Garcia E. Incidence of adverse events related to health care in Spain: Results of the Spanish National Study of Adverse Events. J Epidemiol Community Health. 2008;62(12):1022-1029.

10. Avorn J, ShrankWH. Adverse drug reactions in elderly people: A substantial cause of preventable illness. BMJ. 2008;336(7650):956-957.

11. Ungureanu G, Alexa ID, Stoica O. Iatrogeny and the elderly. Rev Med Chir Soc Med Nat Iasi. 2007;111(4):80-10. Romanian.

12. Fradet G, Legac X, Charlois T, Ponge T, Cottin S. Iatrogenic druginduced diseases, requiring hospitalization, in patients over 65 years of age. 1-year retrospective study in an internal medicine department. Rev Med Interne. 1996;17(6):456-460. French.

13. Pacala JT. Prevention of iatrogenic complications in the elderly. Geriatrics. 2009. Available from: http://www.merckmanuals.com/ professional/sec23/ch342/ch342e.html. Accessed December 31, 2010.

14. Bloch F, Thibaud M, Dugue B, Breque C, Rigaud AS, Kemoun G. Laxatives as a risk factor for iatrogenic falls in elderly subjects: Myth or reality? Drugs Aging. 2010;27(11):895-901.

15. Grabowski DC, Stewart KA, Broderick SM, Coots LA. Predictors of nursing home hospitalization: A review of the literature. Med Care Res Rev. 2008;65(1):3-39.

16. Jahnigen $\mathrm{D}$, Hannon $\mathrm{C}$, Laxson L, LaForce FM. Iatrogenic disease in hospitalized elderly veterans. J Am Geriatr Soc. 1982;30(6):387-390.

17. Forster AJ, Kyeremanteng K, Hooper J, Shojania KG, van Walraven C. The impact of adverse events in the intensive care unit on hospital mortality and length of stay. BMC Health Serv Res. 2008;8:259.

18. Date Y, Ishikawa S, Fujisawa A, Uchida T, Nakazawa K, Makita K. Malposition of epidural catheter: An 8-year retrospective analysis on an incident reporting system at an urban university hospital. Masui. 2010;59(10):1224-1227. Japanese.

19. Permpongkosol S, Bella AJ, Tantarawongsa U, Stoller ML. Laparoscopic extravesical ureteral reimplantation for iatrogenic distal ureteral stricture. J Med Assoc Thai. 2009;92(10):1380-1386.

20. Chattopadhyay S, Pal I. Iatrogenic injuries leading to suspicion of homicide. J Forensic Leg Med. 2008;15(7):447-449.

21. Abdelmoula L, Tekaya R, Ben Hadj Yahia C, Chaabouni L, Zouari R. Morbidity of the elderly in inpatient rheumatology clinic. Tunis Med. 2008;86(4):350-354. French.

22. Bartlett G, Blais R, Tamblyn R, Clermont RJ, MacGibbon B. Impact of patient communication problems on the risk of preventable adverse events in acute care settings. CMAJ. 2008;178(12):1555-1562.

23. Mason A, Weatherly H, Spilsbury K, et al. A systematic review of the effectiveness and cost-effectiveness of different models of communitybased respite care for frail older people and their carers. Health Technol Assess. 2007;11(15):1-157, iii.

24. Victor CR, Higginson I. Effectiveness of care for older people: A review. Qual Health Care. 1994;3(4):210-216.

25. Cormack MA, Sweeney KG, Hughes-Jones H, Foot GA. Evaluation of an easy, cost-effective strategy for cutting benzodiazepine use in general practice. Br J Gen Pract. 1994;44(378):5-8.

26. Kashefi C, Messer K, Barden R, Sexton C, Parsons JK. Incidence and prevention of iatrogenic urethral injuries. J Urol. 2008;179(6): 2254-2257. 
27. Dos Santos JC, Ceolim MF. Nursing iatrogenic events in hospitalized elderly patients. Rev Esc Enferm USP. 2009;43(4):810-817. Spanish.

28. Blinderman CD. Opioids, iatrogenic harm and disclosure of medical error. J Pain Symptom Manage. 2010;39(2):309-313.

29. Fusco D, Lattanzio F, Tosato M, et al. Development of CRIteria to assess appropriate Medication use among Elderly complex patients (CRIME) project: Rationale and methodology. Drugs Aging. 2009; 26 Suppl 1:3-13.
30. Ahmed NN, Pearce SE. Acute care for the elderly: A literature review. Popul Health Manag. 2010;13(4):219-225.

31. Ou ZB, Li SW, Liu CA, et al. Prevention of common bile duct injury during laparoscopic cholecystectomy. Hepatobiliary Pancreat Dis Int. 2009;8(4):414-417.

32. Bunting RF Jr, Benton J, Morgan WD. Practical risk management principles for physicians. J Healthc Risk Manag. 1998;18(4): $29-53$.

\section{Publish your work in this journal}

Clinical Interventions in Aging is an international, peer-reviewed journal focusing on evidence-based reports on the value or lack thereof of treatments intended to prevent or delay the onset of maladaptive correlates of aging in human beings. This journal is indexed on PubMed Central, MedLine, the American Chemical Society's 'Chemical
Abstracts Service' (CAS), Scopus and the Elsevier Bibliographic databases. The manuscript management system is completely online and includes a very quick and fair peer-review system, which is al easy to use. Visit http://www.dovepress.com/testimonials.php to read real quotes from published authors.

Submit your manuscript here: http://www.dovepress.com/clinical-interventions-in-aging-journal 